\title{
Occurrence of Type III Dens Invaginatus and Type I Talon Cusp in Maxillary Lateral Incisor: A Rare Case Report
}

\author{
NB Nagaveni ${ }^{1}$, P Poornima ${ }^{2}$, Shruti Singh ${ }^{3}$, Safina Masroor ${ }^{4}$
}

\begin{abstract}
Aim: To present a case report of concomitant occurrence of dens invaginatus and talon cusp in a single tooth with clinical management using cone-beam computed tomography (CBCT).

Background: Developmental dental anomalies are an important category of dental morphogenic variants. Developmental anomalies of the permanent dentition are most frequently encountered in the maxillary lateral incisor. Talon cusp is an additional cusp that projects predominately from the lingual or occasionally from the labial surface of anterior teeth. This accessory crown structure is composed of enamel, dentine, and varying degrees of pulp tissue. Dens invaginatus is defined as a deep surface invagination of the crown or root that is lined by the enamel.

Case description: A 12-year-old female patient reported with complaint of small swelling in the upper front region of gums. Clinical examination revealed presence of the sinus tract with respect to the permanent maxillary left lateral incisor with morphologic alteration with associated talon cusp. Intraoral periapical radiographic and CBCT examination revealed malformation of the root with the enamel-lined tract mesial to and separate from the main root canal. Large periapical radiolucency approximately sized $1-1.5 \mathrm{~cm}$ was associated with the tract. Root canal treatment of the main root canal as well as of dens invagination followed by apicectomy and cyst enucleation was done.

Conclusion: Co-occurrence of a talon cusp and double dens invaginatus is an extremely rare developmental dental anomaly. This case report represents a talon cusp with dens invaginatus on the maxillary left lateral incisor with associated cyst. Early identification is needed for prevention of potential problems on the affected or opposing tooth.

Clinical significance: This case report presents a management of unusual clinical case of dens invaginatus and talon cusp associated with periapical cyst because of deep infected dens invaginatus using CBCT examination.

Keywords: Apicectomy, Dens invaginatus, Developmental anomaly, Root canal treatment, Talon cusp.

CODS Journal of Dentistry (2018): 10.5005/jp-journals-10063-0041
\end{abstract}

\section{INTRODUCTION}

Developmental dental anomalies are an important category of dental morphogenic variants. Abnormalities in tooth shape, size, and structure result from disturbances during the morphodifferentiation stage of development, while ectopic eruption, rotation, and impaction of teeth result from the developmental disturbances pattern in eruption of permanent dentition. ${ }^{1}$ Developmental anomalies of the permanent dentition are most frequently encountered in the maxillary lateral incisor. This tooth occupies an unfavorable position during its formative stages and is the last of the anterior teeth to calcify; hence, it is the one most likely to be affected by various developmental disturbances. Two such disturbances are dens invaginatus and talon cusp. ${ }^{2}$

Talon cusp is a rare developmental anomaly of teeth, which was first recognized in 1892 by Mitchell. Later on, Mellor and Ripa in 1979 gave the name talon because its shape appeared similar to that of an eagle's talon. It is an additional cusp that projects predominately from the lingual or occasionally from the labial surface of anterior teeth. It is more common in males than females and reported prevalence ranges from less than $1 \%$ to approximately $8 \% .^{3}$ It mainly affects the permanent dentition and majority of the cases are seen in the maxillary teeth where it predominantly occurs in lateral incisors (55\%) followed by central incisors (32\%) and canines (9\%). ${ }^{4}$ Nagaveni et al. reported four cases of coexistence of mesiodens and talon cusp in 2014. ${ }^{5}$ Occurrence of talon cusp in a multilobed mesiodens has also been shown in the literature. ${ }^{6}$

This accessory crown structure is composed of enamel, dentine, and varying degrees of pulp tissue. Mader (1981) defined it as an

\author{
1,2,4 Department of Pedodontics and Preventive Dentistry, College of \\ Dental Sciences, Davangere, Karnataka, India \\ ${ }^{3}$ Department of Pedodontics, Subharti Dental College, Meerut, Uttar \\ Pradesh, India
}

Corresponding Author: NB Nagaveni, Department of Pedodontics and Preventive Dentistry, College of Dental Sciences, Davangere, Karnataka, India, Phone: +918971695506, e-mail: nagavenianurag@ gmail.com

How to cite this article: Nagaveni NB, Poornima P, Singh S, et al. Occurrence of Type III Dens Invaginatus and Type I Talon Cusp in Maxillary Lateral Incisor: A Rare Case Report. CODS J Dent 2018;10(1):16-20.

Source of support: Nil

Conflict of interest: None

additional morphologically well-delineated cusp that projects prominently from the lingual surface and extends at least half the distance from the cementoenamel junction to the incisal edge of primary or permanent anterior teeth. Usually, grooves or fissures are present at the junction of the additional cusp with the lingual tooth surface. ${ }^{3}$ This junctional area often allows plaque retention that may cause caries and endodontic and periodontal inflammation. It is suggested that this condition has a multifactorial etiology combining both genetic and environmental factors. The aberrant hyperactivity of the dental lamina may also be responsible for its occurrence. ${ }^{7}$ It appears to be more prevalent in patients with Rubinstein-Taybi syndrome, Mohr syndrome 
(oral-facial-digital syndrome, type II), Sturge-Weber syndrome (encephalotrigeminal angiomatosis), or incontinentia pigmenti achromians. $^{8}$

Dens invaginatus (dens in dente) was first described by a dentist named "Socrates" in 1856. It is defined as a deep surface invagination of the crown or root that is lined by the enamel. ${ }^{3}$ The prevalence of this anomaly has been found to range from $0.25 \%$ to $5.1 \%$ of the population. It is seen predominantly in the maxilla and the most commonly affected tooth is the maxillary lateral incisor, followed by the maxillary central incisor, premolar, canine, and molar. ${ }^{7}$ The literature has also shown occurrence of dens invaginatus with multiple other anomalies like talon cusp and short root. ${ }^{9}$ It usually occurs unilaterally, but bilateral cases have also been reported. Several theories have been proposed to explain the etiology of dens invaginatus. It has been stated that the invagination could be a result of rapid and aggressive proliferation of a part of the internal enamel epithelium invading the dental papilla. Other factors like injury or infection have also been mentioned as possible causes. However, the exact etiology of dens invaginatus is still controversial. ${ }^{10}$

Both talon cusp and dens invaginatus have been associated with other odontogenic anomalies, such as peg-shaped lateral incisors, dens evaginatus of posterior teeth, supernumerary teeth, congenitally missing teeth, etc. Concomitant occurrence of both talon cusp and dens invaginatus is a rare finding. Table 1 shows simultaneous occurrence of both talon cusp and dens invaginatus in a single tooth. These developmental disturbances are also frequently encountered in the lateral incisor; however, their simultaneous occurrence along with other dental anomalies is uncommon. The following case report presents a management of an unusual clinical case of type III dens invaginatus and type I talon cusp using CBCT.

\section{Case Description}

A 12-year-old female patient reported to the department of pedodontics and preventive dentistry with complaint of small swelling in the upper front region of gums. Clinical examination revealed presence of the sinus tract with respect to the permanent maxillary left lateral incisor with morphologic alteration with associated talon cusp (Figs 1 and 2). The tooth was tender on percussion and palpation and didn't respond to pulp testing. Intraoral periapical radiographic examination revealed malformation of the root with the enamel-lined tract mesial to and separate from the main root canal (Fig. 3). Large periapical pathology approximately sized $1-1.5 \mathrm{~cm}$ was associated with the tract. Cone-beam computed tomography examination was carried out and a diagnosis of type III dens invaginatus associated with necrotic pulp and associated radicular cyst was formulated (Fig. 4). Root canal treatment of the main root canal as well as the dens tract followed by apicectomy and cyst enucleation was planned. The contralateral right lateral incisor appeared normal and was confirmed with help of a radiograph for any similar abnormality owing to often bilateral occurrence of dens invaginatus. Treatment was explained to the patient and concerned parents.

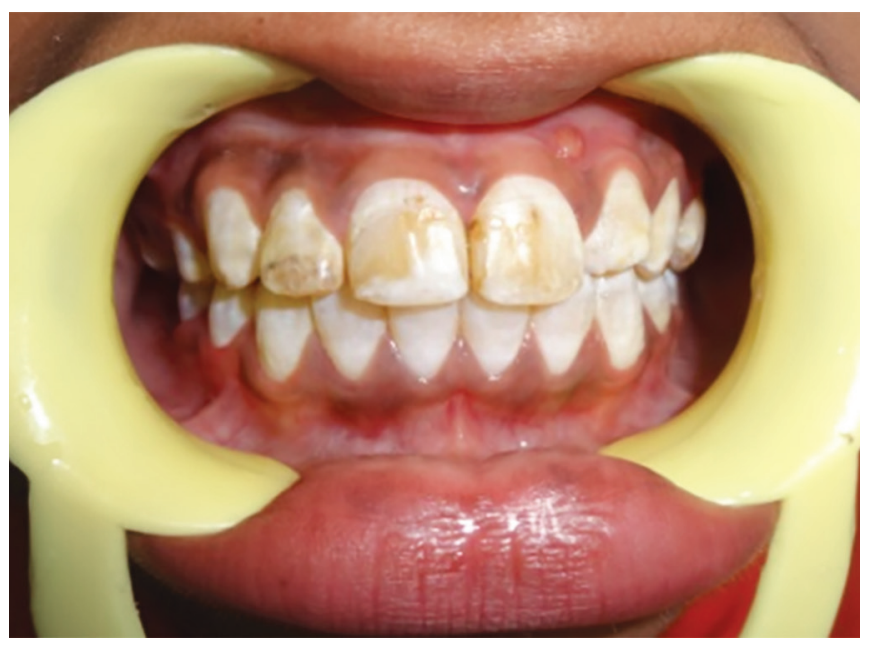

Fig. 1: Preoperative frontal view showing intraoral sinus opening in 22

Table 1: Reported cases of co-occurrence of talon cusp and dens invaginatus in a single tooth

\begin{tabular}{|c|c|c|c|c|c|c|}
\hline S. no. & Author and year & Affected arch & Affected tooth & Talon cusp type & $\begin{array}{l}\text { Dens invaginatus } \\
\text { type }\end{array}$ & Treatment done \\
\hline 1 & Fukuta et al., $1997^{11}$ & Maxilla & Lateral incisor & Type I & Type I & Observation \\
\hline 2 & McNamara et al., $1998^{12}$ & Maxilla & $\begin{array}{l}\text { Central and lateral } \\
\text { incisors }\end{array}$ & Types II and III & Types II and III & $\begin{array}{l}\text { Sealant placement + } \\
\text { endodontic therapy }\end{array}$ \\
\hline 3 & Lorena et al., $2003^{13}$ & Maxilla & Left lateral incisor & Type I & Type II & Observation \\
\hline 4 & Mupparapu et al., $2004^{14}$ & Maxilla & Right lateral incisor & Type I & Type I & Observation \\
\hline 5 & Tiku et al., $2004^{2}$ & Maxilla & Lateral incisor & Type I & Type I & Sealant placement \\
\hline 6 & Anthonappa et al., $2008^{15}$ & Maxilla & Right lateral incisor & Type I & Type II & Sealant placement \\
\hline 7 & Siraci et al., $2008^{8}$ & Mandible & Right central incisor & Type I & Type II & Sealant placement \\
\hline 8 & Sarraf-Shirazi et al., $2010^{16}$ & Maxilla & $\begin{array}{l}\text { Central incisors and left } \\
\text { lateral incisor }\end{array}$ & Type III & Type I & $\begin{array}{l}\text { Sealant placement + } \\
\text { endodontic therapy } \\
\text { with apical MTA plug }\end{array}$ \\
\hline 9 & Nagaveni et al., $2011^{9}$ & Mandible & Left central incisor & Type I & Type I & Sealant application \\
\hline 10 & Gangwar et al., $2014^{17}$ & Mandible & Lateral incisor & Type I & Type II & $\begin{array}{l}\text { Root canal therapy } \\
\text { using MTA apexification }\end{array}$ \\
\hline 11 & Lwin et al., $2017^{18}$ & Maxilla & Right central incisor & Type I & Type I & Sealant application \\
\hline 12 & Present case & Maxilla & Left lateral incisor & Type I & Type III & $\begin{array}{l}\text { Root canal therapy, } \\
\text { apicectomy }\end{array}$ \\
\hline
\end{tabular}




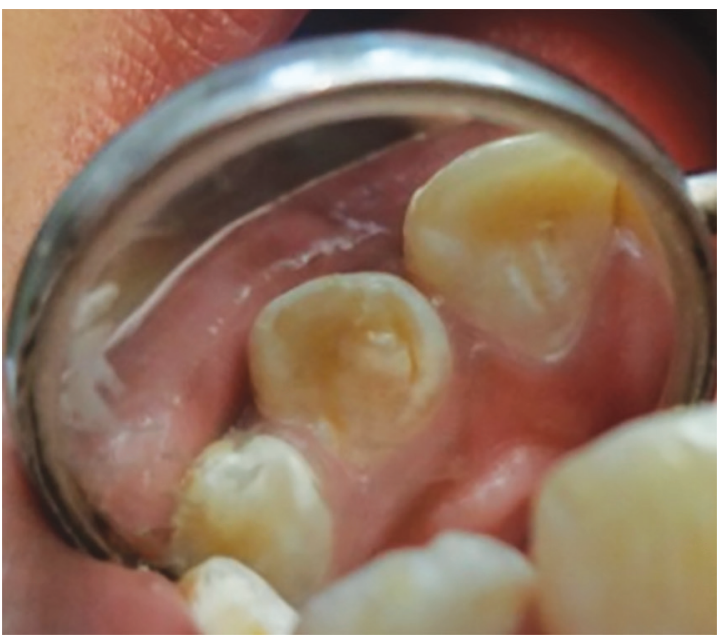

Fig. 2: Maxillary left lateral incisor with talon cusp

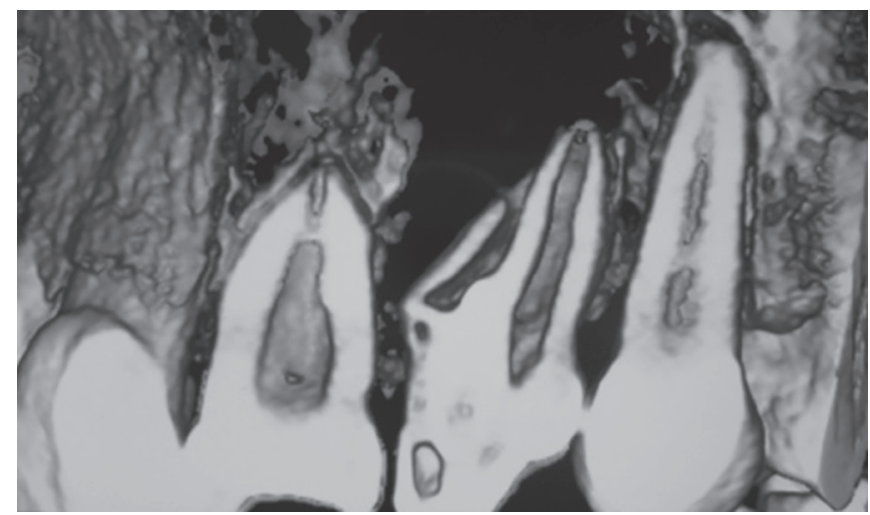

Fig. 4: Preoperative cone-beam computed tomography showing dens in dente and the associated radicular cyst in 22

Under rubber dam isolation, a wide mesiodistal oval-shaped opening was made to achieve adequate access to the invaginated tract as well as to the main pulp canal. Root canal treatment of invagination and the main root canal was planned separately owing to no communication present between them. Working length was obtained for both the canals (Fig. 5). Circumferential filing was used for the main canal. The invaginated tract was also debrided. Root canal irrigants used were $5.25 \%$ sodium hypochlorite and $17 \%$ of ethylene diamine tetraacetic acid. Canals were finally rinsed with saline. Working length was determined with the help of an apex locater (Root ZX, J Morita, Japan), which was further confirmed with a periapical radiograph. Triple antibiotic paste was placed in canals for 2 weeks followed by calcium hydroxide (UltraCal, Ultradent) for 3 weeks to carry out disinfection. The access cavity was sealed with cavit (3M ESPE AG, Seefeld, Germany) between visits to prevent ingress of contaminants.

After 5 weeks, under rubber dam isolation, intentional overobturation was done with gutta-percha of both the main canal and invagination. The root canals were dried with paper points (Maillefer, Dentsply, Ballaigues, Switzerland) and obturated with thermoplastic gutta-percha using the lateral condensation technique and the $\mathrm{AH}+$ sealer (Maillefer, Dentsply, Ballaigues, Switzerland). The tooth was finally restored with composite.

On the same day after the administration of local anesthesia (1:80,000 adrenaline (Lignox, Indoco Remedies Ltd, India), a

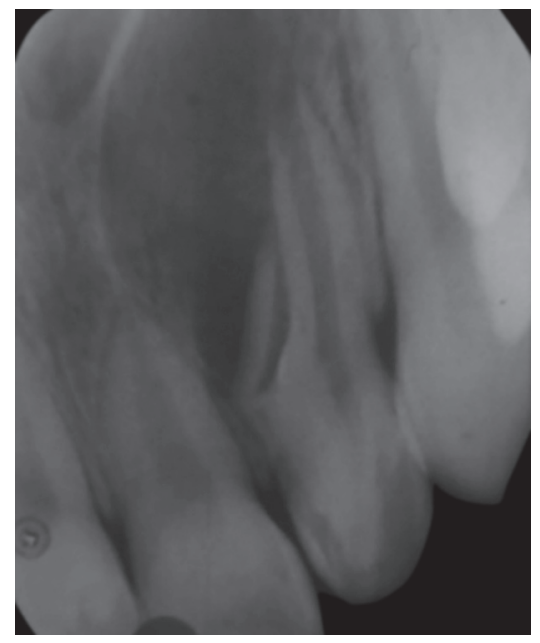

Fig. 3: Preoperative intraoral periapical radiograph of the lateral incisor depicting dens invaginatus along with talon cusp

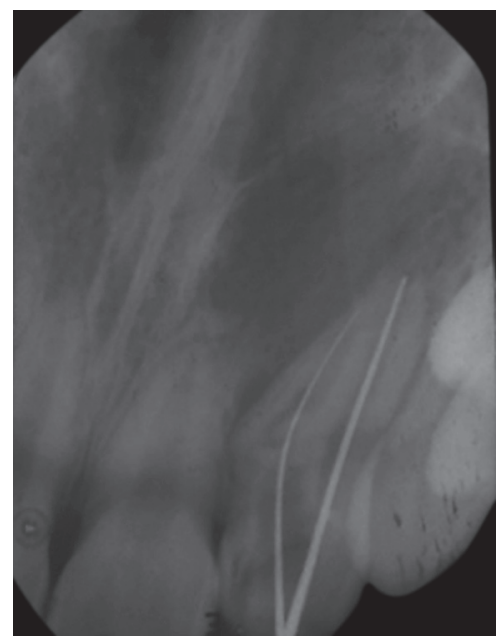

Fig. 5: Intraoral periapical radiograph of working length of the main canal and the dens tract in 22

full-thickness buccal periosteal flap was reflected and the buccal plate overlying the pathology was removed with a surgical bur. The pathological tissue was curetted out with the help of a bone curette. Biodentine was placed through the retrograde approach to seal the communication of the dens tract and the wide apical root canal to periapical area (Fig. 6). Platelet-rich fibrin made up of patients' own blood was used to fill the bone cavity in order to boost healing. Sutures helped the flap to be secured in place. Postsurgery radiovisiography was done (Fig. 7). After 7 days, sutures were removed and uneventful healing was noted. During the follow-up period, the patient was asymptomatic and adequate bone healing was appreciated and is on regular periodic follow-up (Fig. 8).

\section{Discussion}

The permanent maxillary lateral incisor is the most common tooth associated with dens in dente. Due to its complex and variable anatomy, the tooth may present pulp necrosis and open apex, making it difficult to salvage. Hallett was the first person to give classification of dens invaginatus. ${ }^{19}$ But the classification given by 


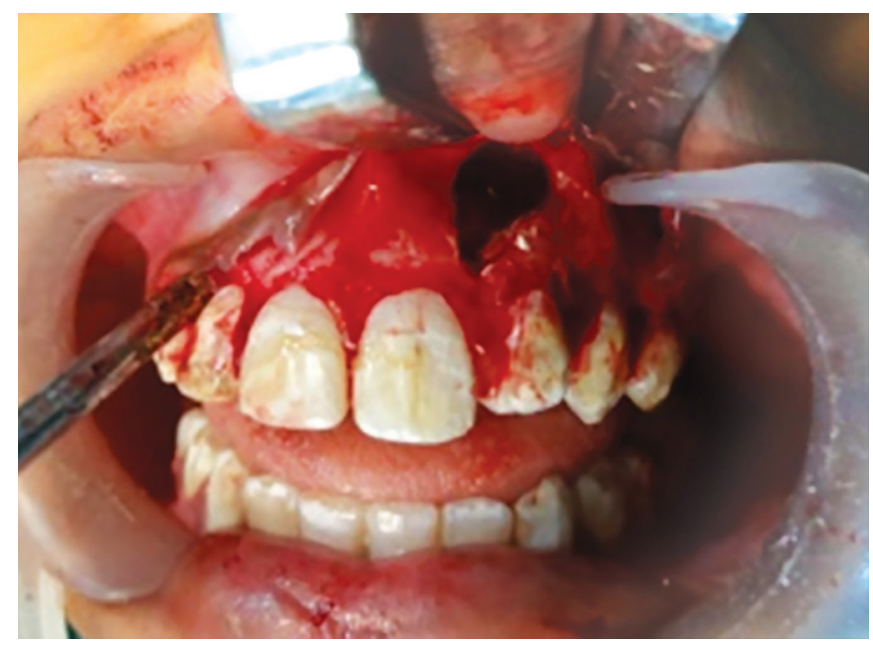

Fig. 6: Intraoperative photograph depicting apicectomy and retrofilling with biodentine in 22

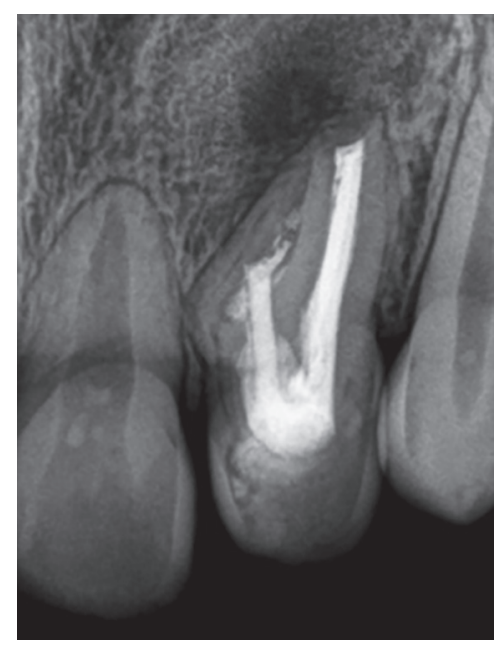

Fig. 8: Radiographic image of 22 at 6-month follow-up

Oehlers $^{\prime 20}$ is the most frequently used. According to him, three forms of dens invaginatus are the following:

- Type I: An enamel-lined minor form that occurs within the confines of the crown without extending beyond the amelocemental junction.

- Type II: An enamel-lined form invading the root but remains as a blind sac. May or may not have communication with the dental pulp.

- Type III: A form that penetrates through the root, perforates apical area showing a "second foramen" in the apical or in the periodontal area with no immediate communication with the pulp. The enamel may completely line the invagination, but frequently cementum can be found lining the invagination.

Schulze and Brand also suggested a detailed classification, where invaginations begins at the incisal edge or the top of the crown and may also include dysmorphic root shapes. The classification has groups $a$ and $b$ with four different variations described in each group. In the first group, the invagination causes division of enamel and dentin. In the second group, the invagination causes division of the pulp chamber into two, along with enamel and dentin. ${ }^{21}$

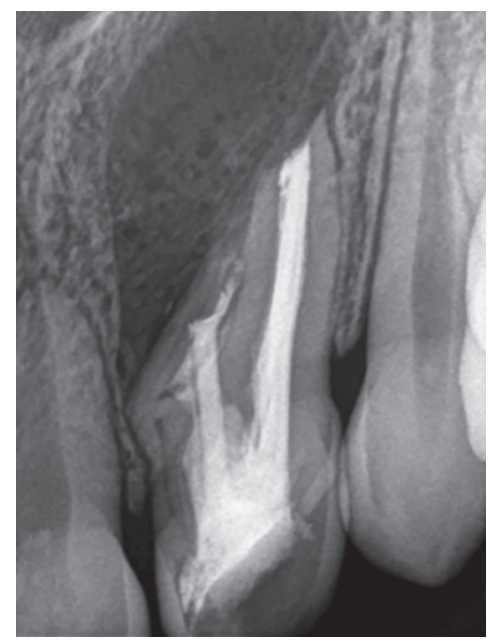

Fig. 7: Immediate postsurgery radiograph

This case was diagnosed as Oehlers type III and Schulze and brand type a-IV with complex internal anatomy requiring challenging treatment for success. Correct knowledge of treatment approaches and available latest materials helps in achieving successful outcomes for such complicated developmental anomalies. An invagination frequently allows the entry of irritants into an area, which is separated from the pulpal tissue by only a thin layer of the enamel. Even sometimes, the enamel lining may be incomplete or channels may exist connecting the invagination and the pulp (Hulsmann). ${ }^{22}$ Usually, infection at this site results in "peri-invagination periodontitis," which leads to the blunderbuss appearance formation. Due to the intimate communication between the root canal and the invagination, if invagination infection occurs, the pulp becomes necrotic. ${ }^{23}$ In the present case too, periapical cyst formation was evident because of deep infected dens invaginatus. Such anomalies have been treated by surgical or nonsurgical procedures and even extraction. However, a more sophisticated treatment plan depends on adequate access and qualitative disinfection and intracanal medicament used during the procedure as owing to presence of necrotic pulp treatment becomes difficult.

Calcium hydroxide was used owing to its positive properties like high alkaline $\mathrm{pH}$, stimulation of the formation of the mineralized tissue, strong bactericidal action, and protein denaturation and hydrolysis, facilitating its dissolution by sodium hypochlorite. ${ }^{24}$ Also Biodentine, a remarkable revolutionary material in dentistry, was used to provide an apical barrier that has amazing properties and sets within 10-12 minutes and owing to its fast setting it allows less chances of bacterial contamination. It has shown successful results as a root end filling material and in management of periapical lesions. ${ }^{25}$

A periapical radiograph was done initially to have overview of the involved tooth but to confirm diagnosis and for knowing extent of pathology and any anatomical variations in canals and root anatomy. Cone-beam computed tomography was carried out, which proved as a fruitful aid in achieving favorable result. It is an effective tool in the diagnosis and endodontic treatment in teeth with anatomical variation and extensive periapical inflammation. It helped in giving a three-dimensional picture and broadening knowledge regarding complex internal anatomy of the culprit tooth. ${ }^{26,27}$ 
Early diagnosis allows to carry out prophylactic treatment, sealing the deep pits and grooves with use of restorative materials to prevent ingress of caries. Other options are endodontic treatment of invagination and the main canal, allowing closure of apex, treatment of canals with retrograde filling, and in severe cases intentional dental replantation. ${ }^{22}$

In the present case, there was association of talon cusp with the dens in dente. Usually small talon cusps are asymptomatic and require no intervention. Large talon cusps may cause occlusal interference, irritation of the tongue during speech and mastication, carious lesions in the developmental grooves that delineate the cusp, pulp necrosis, periapical pathosis, attrition of the opposing tooth, and periodontal disharmony due to excessive occlusal forces. $^{28}$

Such teeth often present thin and fragile root walls and wide apex, and it is critically important to maintain these teeth as long as possible, especially in young patients, to maintain the space until occlusion is established. ${ }^{29}$ In the present case, root canal treatment with proper chemical and mechanical preparation of the main root canal and dens invaginatus in combination with removal of the cyst lining and the biodentine retrograde filling resulted in regression of the periapical pathology with adequate healing at recall visits.

\section{Conclusion}

Dens invaginatus has its clinical implications due to the possibility of pulpal involvement and chronic periapical lesions. Therefore, cautious investigation by the dentist along with knowledge of treatment approaches and timely diagnosis are beneficial to prevent complications. This case report shows that dens invaginatus with an open apex and a radicular cyst can be treated successfully with the better diagnostic and treatment modalities.

\section{References}

1. Gupta SK, Saxena P, Jain S, et al. Prevalence and distribution of selected developmental dental anomalies in Indian population. J Oral Sci 2011;53(2):231-238. DOI: 10.2334/josnusd.53.231.

2. Tiku A, Nadkarni U, Damle SG. Management of two unusual cases of dens invaginatus and talon cusp associated with other dental anomalies. J Indian Soc Ped Prev Dent 2004;22(3):128-133.

3. Nagaveni NB, Umashankar KV. A clinical and radiographic retrospective analysis of talon cusps in ethnic Indian children. I Cranio Max Den 2014;3:79-84. DOI: 10.4103/2278-9588.138214.

4. Kasat VO, Singh M, Saluja H, et al. Coexistence of two talon cusps and two dens invaginatus in a single tooth with associated radicular cyst-a case report and review of literature. J Clin Exp Dent 2014;6(4):430-434. DOI: 10.4317/jced.51421.

5. Nagaveni NB, Shah R, Poornima P, et al. An unusual presentation of mesiodens tooth with talon cusp-report of four cases and literature review. J Res Pract Dent 2014;2014:1836911-1836917. DOI: 10.5171/2013.183691.

6. Nagaveni NB, Umashankar KV, Sreedevi, et al. Multilobed mesiodens with a palatal talon cusp_-a rare case report. Braz Dent J 2010;21(4):375-378. DOI: 10.1590/S0103-64402010000400016.

7. de Sousa SMG, Tavano SMR, Bramante CM. Unusual case of bilateral talon cusp associated with dens invaginatus. Int Endo J 1999;32(6):494-498. DOI: 10.1046/j.1365-2591.1999.00243.x.

8. Siraci E, Gungor HC, Cehreli ZC. Dens invaginatus and talon cusp co-occurring in a mandibular central incisor: a case report. J Dent Child 2008;75(2):177-180.

9. Nagaveni NB, Umashankara KV, Vidyullatha BG, et al. Permanent mandibular incisor with multiple anomalies-report of a rare clinical case. Braz Dent J 2011;22(4):346-350. DOI: 10.1590/S010364402011000400015.
10. Nagaveni NB, Pathak $S$, Anitha $P$, et al. An overview of dens invaginatus with report of 2 cases. J Clin Exp Pathol 2015;5(4):238. DOI: 10.4172/2161-0681.1000238.

11. Fukuta $Y$, Totsuka $M$, Takeda $Y$, et al. A central tubercle on the lingual surface of the upper lateral incisor: report of a case. J Nihon Univ Sch Dent 1997;39(2):86-88. DOI: 10.2334/josnusd1959.39.86.

12. McNamara CM, Garvey MT, Winter GB. Root abnormalities, talon cusps, dens invaginati with reduced alveolar bone levels: case report. Int J Paediatr Dent 1998;8(1):41-45. DOI: 10.1046/j.1365263X.1998.00060.x.

13. Lorena SC, Oliveira DT, Odellt EW. Multiple dental anomalies in the maxillary incisor region. J Oral Sci 2003;45(1):47-50. DOI: 10.2334/ josnusd.45.47.

14. Mupparapu M, Singer SR, Goodchild JH. Dens evaginatus and dens invaginatus in a maxillary lateral incisor: report of a rare occurrence and review of literature. Aust Dent J 2004;49(4):201-203. DOI: 10.1111/j.1834-7819.2004.tb00074.x.

15. Anthonappa RP, Yiu CK, King NM. A novel combination of dens evaginatus and dens invaginatus in a single tooth-review of the literature and a case report. J Clin Pediatr Dent 2008;32(3):239-242. DOI: 10.17796/jcpd.32.3.ex27q2022065pt48.

16. Sarraf-Shirazi A, Rezaiefar M, Forghani M. A rare case of multiple talon cusps in three siblings. Braz Dent J 2010;21(5):463-466. DOI: 10.1590/ S0103-64402010000500015.

17. Gangwar A, Singal D, Giri KY, et al. An immature type II dens invaginatus in a mandibular lateral incisor with talon's cusp: a clinical dilemma to confront. Cas Rep Dent 2014;2014:826294, 1-5. DOI: 10.1155/2014/826294.

18. Lwin HNN, Yaw PP, Thu SWYM. Coexistence of true talon cusp and double dens invaginatus in a single tooth: a rare case report and review of the literature. Clin Cas Rep 2017;5(12):2017-2021. DOI: 10.1002/ccr3.1252.

19. Hallett GE. Incidence, nature, and clinical significance of palatal invaginations in the maxillary incisor teeth. Proc R Soc Med 1953;46(7):491-499. DOI: 10.1177/003591575304600703.

20. Oehlers FA. Dens invaginatus (dilated composite odontome). I. Variations of the invagination process and associated anterior crown forms. Oral Surg Oral Med Oral Pathol 1957;10(11):1204-1218. DOI: 10.1016/0030-4220(57)90077-4.

21. Schulze C, Brand E. Über den dens invaginatus (dens in dente). ZWR 1972;81(12):569-573, 613-620, 653-660, 699-703.

22. Hülsmann M. Dens invaginatus: aetiology, classification, prevalence, diagnosis, and treatment considerations. Int Endod J 1997;30(2): 79-90. DOI: 10.1111/j.1365-2591.1997.tb00679.x.

23. Alani A. Dens invaginatus: a problem from the outside in. Int Dent J 2009;59(6):343-348.

24. Steffen $\mathrm{H}$, Splieth $\mathrm{C}$. Conventional treatment de dens invaginatus in maxillary lateral incisor with sinus tract: one year follow-up. J Endod 2005;31(2):130-133. DOI: 10.1097/01.don.0000137637. 94281.82.

25. Pawar AM, Kokate SR, Shah RA. Management of a large periapical lesion using Biodentine $\left({ }^{\mathrm{T} M}\right)$ as retrograde restoration with eighteen months evident follow up. J Conserv Dent 2013;16(6):573-575. DOI: 10.4103/0972-0707.120934.

26. Vier-Pelisser FV, Pelisser A, Recuero LC, et al. Use of cone beam computed tomography in the diagnosis, planning and follow up of a type III dens invaginatus case. Int Endod J 2012;45(2):198-208. DOI: 10.1111/j.1365-2591.2011.01956.x.

27. Kaneko T, Sakaue H, Okiji T, et al. Clinical management of dens invaginatus in a maxillary lateral incisor with the aid of conebean computed tomography: a case report. Dent Traumatol 2011;27(6):478-483. DOI: 10.1111/j.1600-9657.2011.01021.x.

28. Hattab FN, Hazza'a AM. An unusual case of talon cusp on geminated tooth. J Can Dent Assoc 2001;67(5):263-266.

29. Rocha Neto PCR, Oliveira LC, Oliveira MDC, et al. Dens invaginatus: case report. RGO 2015;63(2):219-226. DOI: 10.1590/1981863720150002000132564 . 